\title{
A ALFABETIZAÇÃO NO ENSINO FUNDAMENTAL DE NOVE ANOS NO CONTEXTO DAS POLÍTICAS EDUCACIONAIS: ALGUNS DESAFIOS PARA REFLEXÃO
}

\author{
LA ALFABETIZACIÓN EN LA ENSEÑANZA FUNDAMENTAL DE \\ NUEVE AÑOS EN EL CONTEXTO DE LAS POLÍTICAS EDUCACIONALES: \\ ALGUNOS DESAFÍOS PARA REFLEXIÓN
}

\author{
ALPHABETIZATION IN NINE YEARS - BASIC EDUCACION IN THE \\ CONTEXT OF EDUCATIONAL POLICIES: SOME CHALLENGES FOR \\ REFLECTION
}

Leonete Luzia SCHMIDT ${ }^{1}$ Letícia Carneiro AGUIAR ${ }^{2}$

\begin{abstract}
RESUMO: O artigo faz reflexões sobre os desafios que a perspectiva da alfabetização com letramento apresenta para os três primeiros anos do Ensino Fundamental, no contexto das políticas de ampliação deste ensino, sobretudo num momento em que a Lei $\mathrm{n}^{\mathrm{o}}$ 11.274/06 (BRASIL, 2006) completa dez anos de sua promulgação, e na qual foram definidos os três primeiros anos como tempo destinado à alfabetização e letramento. Foram trabalhados dados obtidos nos microdados do Censo Escolar e nos resultados da Avaliação Nacional da Alfabetização de 2014, cujas análises ocorreram durante o desenvolvimento de pesquisas aprovadas por Editais do Observatório da Educação (CAPES/INEP). Os resultados evidenciaram que um contingente significativo de crianças está chegando ao final do ciclo alfabetizador sem saber ler e escrever, e em escolas com precárias condições materiais e pedagógicas, o que demonstra que o processo de ensino e a aprendizagem ocorrem em condições que fragilizam a continuidade nos estudos e a participação ativa da criança na vida social.
\end{abstract}

PALAVRAS-CHAVE: Alfabetização com letramento. Ampliação do ensino fundamental. Política Educacional para a Alfabetização. Ciclo alfabetizador.

RESUMEN: El artículo desarrolla reflexiones sobre los desafíos que la perspectiva de la alfabetización con aprendizaje de lectoescritura ("letramento") presenta para los tres primeros años de la Enseñanza Fundamental, en el contexto de las políticas de ampliación de esta enseñanza, sobre todo en un momento en que la Ley $n^{o} 11.274 / 06$ (BRASIL, 2006) cumple diez años de su promulgación, y en la cual fueron definidos los tres primeros años como tiempo destinado a la alfabetización y al aprendizaje de lectoescritura ("letramento"). Fueron trabajados datos obtenidos en los microdatos del "Censo Escolar" y en los resultados de la Evaluación Nacional de la Alfabetización de 2014, cuyos análisis ocurrieron a lo largo del desarrollo de investigación aprobadas por Convocatorias del Observatorio de la Educación (CAPES/INEP). Los resultados evidenciaron que un contingente significativo de niños llega al fin de alfabetización sin saber leer y escribir, y en escuelas con precarias condiciones materiales y pedagógicas, lo que demuestra que el proceso de enseñanza y el aprendizaje ocurren en condiciones

\footnotetext{
${ }^{1}$ Doutora em Educação. Universidade do Sul de Santa Catariana, UNISUL. Professora do Programa de pós-graduação em Educação, Tubarão, Brasil. E-mail: leonetes@ gmail.com.

${ }^{2}$ Doutora em Educação. Universidade do Sul de Santa Catariana, UNISUL. Professora do Programa de pós-graduação em Educação, Tubarão, Brasil. E-mail: leticia.aguiar@unisul.br.
} 
que fragilizan la continuidad en los estudios y la participación activa del niño en la vida social.

PALABRAS CLAVE: Alfabetización con aprendizaje de lectoescritura ("letramento"). Aplicación de la enseñanza fundamental. Políticas educacionales para la alfabetización. Ciclo de alfabetización.

ABSTRACT: The article reflects on the challenges that the overview of alphabetization with literacy presents for the first three years of primary school, in the context of expansion policies of this education, especially at the time when the Law Number 11.274/06 (BRASIL, 2006) completes ten years of its enactment and in which were defined the first three years as a time devoted to alphabetization and literacy. Some data were obtained and worked in the School Census microdata and the results of Literacy National Assessment in 2014, whose analyzes occurred during the development of researches approved by Edicts from the Education Observatory (CAPES / INEP). The results showed that a significant number of children are coming to the end of the literacy cycle without knowing how to read and write, and in schools substandard materials and pedagogical conditions, which shows that the process of teaching and learning take place in conditions that weaken the continuity of studies and the active participation of children in social life.

KEYWORDS: Alphabetization with literacy. Basic Education Expansion. Educational Policy for Alphabetization. Literacy cycle.

\section{Introdução}

Este artigo é resultado de pesquisas desenvolvidas a partir de 2010, cujos projetos foram financiados pelo Programa Observatório da Educação - CAPES/INEP, através do Edital $n^{\circ}$ 8/2010, desenvolvido no período 2010-2013, e do Edital $n^{\circ}$ 49/2012, no período 2013-2017. Tendo como referência as políticas públicas para o Ensino Fundamental (EF), no contexto das reformas educativas induzidas pela reestruturação produtiva, a ideologia da globalização, o neoliberalismo e uma progressiva ditadura do mercado, que produzindo um emblemático desmanche da Educação Básica e de um retorno ao neopragmatismo e economicismo, essas pesquisas focalizam problemáticas relacionadas ao processo de alfabetização, tais como a perspectiva da alfabetização com letramento, a formação e o trabalho docente, a gestão escolar, o ciclo alfabetizador e as práticas pedagógicas em escolas públicas.

O que neste artigo se pretende socializar é resultado das pesquisas focalizadas na problemática da alfabetização com letramento, tendo como recorte os desafios que ainda precisam ser enfrentados pelo sistema público de ensino em relação à alfabetização de 
crianças nos três primeiros anos do EF a partir da proposição/implantação da política de ampliação do EF.

A decisão política de ampliar o EF para nove anos é positiva, sobretudo para as camadas mais pobres da população que constituem a grande maioria da escola pública fundamental básica. Todavia, por si só, não garante nada. No momento em que se completam dez anos da aprovação da Lei n 11.274, de 06/02/2006 (BRASIL, 2006), é mais que pertinente colocar como uma questão central para pensar a ampliação do tempo escolar para nove anos, os desafios a serem enfrentados para a efetivação dessa política, principalmente o desafio de efetivar uma política de Educação Básica que resgate o direito de seguir se escolarizando para aqueles a quem isso foi negado até o presente e, sobretudo, universalize o acesso na idade apropriada, garanta a permanência com efetiva democratização do conhecimento.

A universalização do acesso ao EF na virada do milênio é, sem dúvida, uma grande conquista para a educação brasileira. No entanto, há um contingente significativo de crianças que nem sequer estão sendo alfabetizadas. Das crianças matriculadas, no ano de 2012 no $3^{\circ}$ ano de escolas públicas, 12,6\% reprovaram e 21,3\% se encontravam em distorção idade/série (BRASIL, 2014). No estado de Santa Catarina, no ano de 2013, das crianças matriculadas no $3^{\circ}$ ano do EF das escolas públicas, $7 \%$ reprovaram e 9,4\% se encontravam na condição de distorção idade/série (BRASIL, 2013), o que corresponde a um total de 6.404 crianças reprovadas no final do ciclo alfabetizador neste estado. E se forem considerados as crianças e jovens que nem sequer frequentam a escola, segundo o Censo Escolar de 2010, é possível perceber que havia um contingente de 3,8 milhões, ou seja, cerca de $8,5 \%$ da população desta faixa etária (composta de 45,4 milhões) e, destaca-se, são majoritariamente os mais pobres, os negros e os que vivem no campo.

Esses são alguns dados que exemplificam que ainda há um contingente da população escolar, logo no início de sua trajetória na escola, que está à margem do processo de apropriação da leitura e da escrita, conhecimentos esses científicos indispensáveis para a continuidade dos estudos e para a participação ativa na sociedade atual. Saber ler e escrever de forma rudimentar não é uma condição suficiente para garantir permanência na escola com sucesso e participação ativa e crítica no contexto social e cultural existente.

O discurso oficial afirma que o acesso à escola está universalizado, e que resta agora buscar a qualidade. Produzir um salto de qualidade na educação, a partir da 
inclusão de todas as crianças, permanência na escola, sucesso na aprendizagem, aumento da escolaridade etc., foram argumentos apresentados pelo Ministério da Educação (MEC) para justificar a ampliação do EF (BRASIL, 2004). Mas que qualidade é essa, cuja afirmação tem sido recorrente nos documentos de política educacional? Aquela que atribui certificados de concluintes a cada etapa da Educação Básica - mesmo quando a grande maioria é classificada como analfabeta funcional -, ou daquela na qual o sujeito apropria-se dos conhecimentos do saber científico e dele tem condições de fazer uso social? Educação de qualidade entende-se como aquela que assegura a todos a apropriação do saber historicamente produzido, dando a eles condição de fazer uso na sua prática social.

Uma das estratégias adotadas pelo Estado para resolver o problema da qualidade da educação foi a ampliação do tempo do EF de oito para nove anos, através da Lei $\mathrm{n}^{\circ}$ 11.274/2006 (BRASIL, 2006), acrescentando um ano na etapa inicial da alfabetização e a definição do "ciclo da infância" com três anos de duração, ratificando que este é um período dedicado à alfabetização e ao letramento, ao desenvolvimento das diversas expressões e ao aprendizado das áreas de conhecimento (BRASIL, 2008). A partir dessa definição legal, a alfabetização no ciclo inicial do EF de nove anos deve proporcionar a alfabetização e o letramento das crianças, o que implica numa alfabetização plena, ou seja, a apropriação do código articulada ao contexto e práticas sociais. Assegurar uma alfabetização plena se constitui num desafio a ser concretizado, considerando-se os índices de reprovação, de distorção idade-série, de domínio da leitura e da escrita, de condições precárias de trabalho docente nas escolas públicas, etc.

Neste sentido, este artigo tem a finalidade de refletir sobre a perspectiva de alfabetização e letramento propostos para os três primeiros anos do EF de nove anos a partir da Lei $n^{\circ}$ 11.274/06 (BRASIL, 2006), com destaque para os desafios advindos dessa determinação legal, diante de uma realidade estatística relativas aos índices de acesso, permanência e aproveitamento escolar apontando que, na prática, a conquista deste direito ainda está aquém da realidade almejada por grande parte da sociedade brasileira, e de que ainda se está longe de concretizar uma educação pública de qualidade. 


\section{A Lei $n^{0}$ 11.274/2006 no contexto das reformas da educação}

A Lei $n^{\circ} 11.274 / 2006$ (BRASIL, 2006) que amplia o EF é uma política pública inserida no contexto das macropolíticas de reforma do sistema educacional, formulado pelos organismos internacionais para os países de economia capitalista, mais especificamente para os países periféricos em relação à expansão da Educação Básica. Nos documentos do governo brasileiro elaborados para orientar a implantação do ensino de nove anos, há uma preocupação em atenuar o baixo índice de alfabetização no país. O que não significa, necessariamente, investir na melhoria da qualidade de vida das pessoas, mas, primordialmente, para atender novas exigências do capital que, a partir da década de 1970, em seu processo de reestruturação produtiva para minimizar sua crise de expansão e acumulação, levou às transformações na produção da vida material objetiva e subjetiva. Transformações essas que “[...] ocorrem na esfera do Estado, da produção, do mercado e também no âmbito ideológico-político-cultural, em consequência dos processos de Reestruturação Produtiva, da Globalização e do Neoliberalismo". (PERONI, 2006, p.11).

No sistema capitalista de produção o Estado tem um papel abrangente na perpetuação da estrutura de classe, e elabora políticas sociais que asseguraram a reprodução do capital, na medida em se encontra diretamente envolvido com o seu processo de expansão e acumulação, direcionando as políticas públicas em geral, visando, por meio de políticas compensatórias, a administrar os conflitos e as tensões entre classes sociais. As políticas sociais não se constituem num processo natural, mas histórico, mediadas que estão por relações sociais conflitivas, não apenas entre capital e trabalho, mas também entre as diferentes frações do capital, pois o Estado cumpre a tarefa de harmonizar os distintos interesses em competição, legitimando ao mesmo tempo a ordem social (FINKEL, 1990).

A escola, como instituição social, não está isenta dos conflitos de classes existentes no seio da sociedade em geral. No seu interior, e fora dela, a questão da luta de classes evidencia uma luta pelo acesso e controle do conhecimento científico, do conhecimento histórico e socialmente produzido pela humanidade. Como ressaltam Gentili e Silva (2007), existem estratégias específicas para a educação institucionalizada, pois ela integra os complexos e eficientes mecanismos de representação e significação utilizados para criar e recriar um clima favorável à perspectiva socioeconômica e política neoliberal. Para tanto, à educação escolar são 
atribuídos os objetivos de: qualificar a força de trabalho com o perfil necessário do nível instrucional, da capacidade de adaptabilidade às mudanças no processo de trabalho, colocando-a em condições de aprender; contemplar a necessidade de oferecer um mínimo de conteúdos e o máximo em disciplina psicofísica à população excluída do emprego formal e regulamentado, possibilitando às pessoas procurar ocupações alternativas na esfera informal ou no trabalho autônomo; atenuar as disparidades sociais e conter as possibilidades de conflito; retirar da marginalidade setores economicamente excluídos, formando um novo perfil sociopsicológico de trabalhador - socialmente integrado, competitivo, consumidor, e que individualmente assume a culpa pelo seu sucesso e fracasso.

Entende-se que as políticas públicas de universalização e ampliação do EF e a focalização neste nível de ensino como prioridade, a ampliação do direito à educação de todos os indivíduos, podem ser interpretadas como o seguimento do Brasil às recomendações dos eventos e dos organismos internacionais, que atuam na construção de um consenso mundial sobre as estratégias adequadas para inserir a educação nos rumos do desenvolvimento socioeconômico capitalista. A partir de 1990, a participação do Brasil nesse processo começa a efetivar-se, quando assume, entre outros compromissos, na Conferência Mundial de Educação para Todos, promovida pela UNESCO e a UNICEF (UNESCO, 1990), com o apoio do Banco Mundial, junto com outros 155 países, o compromisso de assegurar uma Educação Básica de qualidade às crianças, jovens e adultos, resultando em consensos que deveriam penetrar a formulação dos planos decenais de educação, em especial nos países mais populosos e com os maiores índices de analfabetismo do mundo (SHIROMA; MORAES; EVANGELISTA, 2002; OLIVEIRA, 2000).

Para Oliveira (2000), as reformas educacionais deflagradas nesse período pretenderam preparar a população para que se integrasse à sociedade atual e, mais recentemente, para a empregabilidade. Segundo Aguiar (2012, p.24),

Importante ressaltar que o conceito de empregabilidade se presta muito mais para encobrir do que explicar a realidade do crescimento da taxa de desemprego, do aumento significativo do emprego precário, da queda generalizada dos salários, pois sua definição referese à capacidade dos trabalhadores manterem-se empregados, encontrar novos empregos quando demitidos, na medida em que possuem a capacidade de responder aos requisitos de qualificação demandados pelo mercado de trabalho. 
Assim, as políticas de expansão da Educação Básica e, neste caso em específico, de valorização e ampliação do EF, estão sistematicamente sendo propostas pelo governo brasileiro desde a década de 1990, iniciando com a proposição e aprovação da Lei do Fundo de Manutenção e Desenvolvimento do Ensino Fundamental e de Valorização do Magistério (FUNDEF) Lei no 9.424, de 1996 (BRASIL, 2001a). Em termos legais, a proposta de ampliação do EF estava sinalizada pela LDB/96, que em seu artigo 87, § $3^{\circ}$, previa a matrícula facultativa a partir dos seis anos de idade, e com a alteração que lhe foi realizada a partir da aprovação da Lei no 11.114, de 16/05/2005 (BRASIL, 2005), que altera a redação dos artigos 6, 30, 32 e 87 da LDB, tornando o EF com a duração mínima de oito anos, obrigatório e gratuito a partir dos seis anos. Essa proposição também estava contida no Plano Nacional de Educação (PNE) 2001-2011, Lei n $^{\text {o }}$ 10.172/2001 que, ao tratar dos objetivos e metas do EF, já propunha a sua "[...] ampliação para nove anos com início aos 6 anos de idade, à medida que fosse universalizado o atendimento da faixa etária dos 7 aos 14 anos”. (BRASIL, 2001b).

O processo de mudança, no entanto, efetiva-se a partir de 2004, quando o MEC põe em debate a ampliação do EF, realizando sete eventos regionais e um nacional, com a parceria do Conselho Nacional de Secretários de Educação (CONSED) e a União Nacional dos Dirigentes Municipais de Educação (UNDIME). O Ministério também publica em 2004, o documento "Ensino Fundamental de Nove Anos: orientações gerais", uma síntese dos debates ocorridos nos encontros regionais e que se tornou uma referência para as questões pedagógicas e administrativas relativas ao ingresso das crianças de seis anos de idade no EF (BRASIL, 2004). E em 2006, publica o documento "Ensino Fundamental de nove anos - orientações para a inclusão da criança de seis anos de idade", de caráter mais teórico.

Em maio de 2005, a Lei n 11.114 é sancionada, alterando os artigos $6^{\circ}, 32$ e 87 da LDB/96 referentes à obrigatoriedade da entrada das crianças aos seis anos de idade no EF, sem citar, ainda, a questão da ampliação desse ensino para nove anos. Até a aprovação da lei, a idade mínima para a matrícula obrigatória no EF era de sete anos (BRASIL, 2005). Na sequência, através da Resolução no 3, de 03/08/2005, o Conselho Nacional de Educação (CNE), define normas nacionais para a ampliação do EF para nove anos de duração, ressaltando a necessidade de vincular a obrigatoriedade da entrada das crianças aos seis anos de idade (BRASIL, 2005). Mas, foi somente com a Lei $\mathrm{n}^{\circ} 11.274 / 2006$ que se materializa a alteração dos artigos 32 e 87 da LDB/96, instituindo a ampliação do EF de nove anos de duração, com matrícula obrigatória a 
partir dos seis anos de idade, além de estabelecer o prazo até 2010 para o seu cumprimento (BRASIL, 2006).

Após a publicação dessa lei, outros dispositivos legais foram aprovados para orientar a organização do currículo de nove anos, como: o Decreto $\mathrm{n}^{\circ}$ 6.094, de 24/04/2007 (BRASIL, 2007) que institui o Plano de Metas "Compromisso Todos pela Educação", determinando em seu artigo 20 inciso II, “[...] alfabetizar as crianças até, no máximo, os oito anos de idade, aferindo os resultados por exame periódico específico"; o Parecer CNE/CEB n ${ }^{\circ}$ 4, de 20/02/2008 (BRASIL, 2008), que “[...] orienta sobre o tratamento pedagógico para os três primeiros anos do EF"; a Resolução CNE/CBE n ${ }^{0} 7$, de 14/12/2010 (BRASIL, 2010), na qual são ratificadas as Diretrizes Curriculares Nacionais para o EF de nove anos, com orientações específicas às séries iniciais, organizadas em cinco anos, e as finais, em quatro anos. Quanto às séries iniciais, dá ênfase ao ciclo alfabetizador, esta Resolução de 2010 define em seu artigo 30:

Os três anos iniciais do Ensino Fundamental devem assegurar:

I - a alfabetização e o letramento;

II - o desenvolvimento das diversas formas de expressão, incluindo o aprendizado da Língua Portuguesa, a Literatura, a Música e demais artes, a Educação Física, assim como o aprendizado da Matemática, da Ciência, da História e da Geografia;

III - a continuidade da aprendizagem, tendo em conta a complexidade do processo de alfabetização e os prejuízos que a repetência pode causar no Ensino Fundamental como um todo e, particularmente, na passagem do primeiro para o segundo ano de escolaridade e deste para o terceiro. (BRASIL, 2010, p.8).

Diante deste arcabouço legal, o MEC define como objetivos da ampliação do EF para nove anos de duração:

a) melhorar as condições de equidade e de qualidade da Educação Básica;

b) estruturar um novo ensino fundamental para que as crianças prossigam nos estudos, alcançando maior nível de escolaridade;

c) assegurar que, ingressando mais cedo no sistema de ensino, as crianças tenham um tempo mais longo para as aprendizagens da alfabetização e do letramento. (BRASIL, 2009, p.3).

Ao estabelecer esses objetivos, o MEC afirma que sua intenção é proporcionar às crianças de seis anos de idade o ingresso mais cedo e conclusão do EF aos catorze anos, uma vez que, segundo o Ministério, referenciado em alguns estudos, as crianças ao entrarem mais cedo no ambiente escolar, possivelmente, terão melhores resultados na aprendizagem do que as que ingressam com sete anos. Nesse ponto, supõe contribuir 
para a equidade social e a qualidade da educação; bem como aumentar as oportunidades de aprendizagem à medida que amplia o tempo das crianças na escolarização, a partir dos seis anos.

Contudo, ainda que tais mudanças possibilitem o acesso e a permanência de mais crianças das classes populares na escola, a qualidade do ensino encontra-se seriamente comprometida quando se refere ao nível de aprendizagem efetiva das crianças e jovens, à apropriação dos conhecimentos.

No Brasil, segundo o INEP (BRASIL, 2013b), tem-se que a proporção da população de 12 anos de idade com ao menos os anos iniciais do EF concluídos é de 62\%, sendo que em Santa Catarina esse percentual é de 68\%. Dados da Avaliação Nacional de Alfabetização (ANA) (BRASIL, 2013a) indicam que dos 2,6 milhões de alunos do $3^{\circ}$ ano do EF, nas 55.000 escolas públicas existentes no país, uma em cada quatro crianças não sabia ler ou fazer as operações aritméticas simples, sendo que em torno de $45 \%$ não sabia escrever corretamente um texto simples. Microdados do Sistema de Avaliação da Educação Básica/INEP de 2013 (TODOS PELA EDUCAÇÃO, 2016b) informam que a porcentagem de alunos que aprenderam o que seria adequado ao final de cada etapa de educação, era a seguinte em Português: $5^{\circ}$ ano, 45\%; $9^{\circ}$ ano, 29\%; e $3^{\circ}$ ano do Ensino Médio (EM) 27\%. Na Matemática a situação era: $5^{\circ}$ ano, $40 \%$; $9^{\circ}$ ano, $16 \%$; e $3^{\circ}$ ano do EM, $9 \%$.

Para Callegari (2015, p.1), considerando esses resultados da ANA (BRASIL, 2013a), o que “[...] esperar de um país que nem sequer consegue alfabetizar todas as suas crianças? É tão difícil fazer isso? Que futuro terão esses meninos e meninas cujos direitos de aprendizagem e de desenvolvimento são sonegados?”. Observa o autor que “[...] aos oito anos de idade essas crianças já estão em situação que determina precocemente que terão sérias dificuldades na sua trajetória educacional e de vida, e essa situação é raiz para a desigualdade social e a exclusão". (CALLEGARI, 2015, p.1).

Ao propor as Metas 2 e 5, o atual PNE 2014-2024 (BRASIL, 2014) também evidencia essa dura realidade, demonstrando que a universalização do EF e a alfabetização de todas as crianças até o final do ciclo alfabetizador constituem-se numa realidade a ser alcançada. Afirma o PNE na Meta 2: “[...] universalizar o ensino fundamental de 9 (nove) anos para toda a população de 6 (seis) a 14 (quatorze) anos e garantir que pelo menos $95 \%$ (noventa e cinco por cento) dos alunos concluam essa etapa na idade recomendada, até o último ano de vigência deste PNE”; e na Meta 5 “[...] 
alfabetizar todas as crianças, no máximo, até o final do $3^{-}$(terceiro) ano do ensino fundamental”. (BRASIL, 2014).

Não desconsiderando o contexto político-econômico no qual ocorrem reformas na educação brasileira, como é o caso aqui da ampliação do EF, é preciso não perder de vista que a Lei $\mathrm{n}^{\circ}$ 11.274/2006 (BRASIL, 2006) aponta uma perspectiva mais inovadora em relação à concepção de alfabetização proposta - a alfabetização com letramento. Como indicado inicialmente, esta perspectiva de alfabetização impõe determinados desafios quando se compreende que a educação escolar pública deve garantir a todos uma educação com qualidade social. É o que propomos refletir a seguir.

\section{A alfabetização com letramento: desafios para uma educação de qualidade}

Os conceitos de alfabetização e letramento a que se refere o Parecer $n^{\circ} 4 / 2008$ (BRASIL, 2008) estão ancorados nos estudos de Magda Soares, que, desde a década de 1980, tem desenvolvido estudos e pesquisas sobre alfabetização. Soares (2004), é preciso mais que alfabetizar, tem que se alfabetizar de maneira que a criança saiba mais que ler e escrever; que ela saiba fazer uso dessa leitura e escrita na sua vida. Essa é a proposta do alfabetizar letrando. De acordo com a autora, um conceito que está em evidência no cenário atual da educação é o de letramento, que pode ser entendido como “[...] o processo de apropriação da cultura escrita, fazendo um uso real da leitura e da escrita como práticas sociais". (SOARES, 2004, p.24).

A partir dessa concepção, é possível perceber que a criança torna-se alfabetizada e letrada quando aprende a ler e a escrever e utiliza esses recursos em diferentes situações e contextos. Pensando nessa perspectiva, o grande desafio da educação nos dias atuais é garantir o processo de alfabetizar letrando. Na concepção de Tfouni (2006, p.34), “[...] enquanto a alfabetização ocupa-se da aquisição da escrita, o letramento concentra-se dos aspectos sócio históricos da aquisição de um sistema escrito por uma sociedade".

Ainda sobre alfabetizar letrando, “[...] não basta apenas saber ler e escrever, é preciso também fazer uso do ler e do escrever, saber responder às exigências de leitura e de escrita que a sociedade faz continuamente." (SOARES, 2004, p.20). Nas palavras da autora: 
Porque alfabetização e letramento são conceitos frequentemente confundidos e sobrepostos, é importante distingui-los, ao mesmo tempo que é importante também aproximá-los: a distinção é necessária porque a introdução, no campo da educação, do conceito de letramento tem ameaçado perigosamente a especificidade do processo de alfabetização; por outro lado, a aproximação é necessária porque não só o processo de alfabetização, embora distinto e específico, altera-se e reconfigura-se no quadro do conceito de letramento, como também este é dependente daquele. (SOARES, 2003, p.90).

A preocupação da autora em relação à referida ameaça, é que se atribua, como ocorreu na década de 1980, quando se substituiu como se ensina para o como se aprende, maior importância ao processo e ao contexto social no qual a escrita está inserida em detrimento do ensino e da aprendizagem do código da escrita. Quando se compreende que há uma unidade indissolúvel entre alfabetizar e letrar, é preciso assegurar que as duas dimensões - a do domínio do código e a compreensão do sistema da escrita - estejam presentes no processo de alfabetização.

Nesse sentido, para que a criança tenha sucesso no processo de alfabetização, o ambiente deve ser considerado. Se o meio em que ela vive não lhe proporciona acesso e práticas cotidianas com a leitura e a escrita, a escola passa a ser o lugar a que ela tem acesso a esses bens culturais, o que torna a escola indispensável, se se trabalhar na perspectiva da inclusão de todos no mundo letrado. Para que a criança tenha uma alfabetização plena, é preciso que ela se aproprie do mundo no qual vive.

De acordo com Soares (2004, p.39),

Ter-se apropriado da escrita é diferente de ter aprendido a ler e a escrever: aprender a ler e a escrever significa adquirir uma tecnologia, a de codificar em língua escrita e a de decodificar a língua escrita; apropriar-se da escrita é tornar a escrita própria, ou seja, é assumi-la como sua 'propriedade'.

O processo pelo qual vai se consolidando a concepção de alfabetização com letramento ocorre desde a infância, quando as crianças entram em contato com as mais variadas formas de linguagem, entre elas a linguagem escrita, bem como a oralidade, através da fala das crianças.

Ao analisar os resultados da ANA (BRASIL, 2013), é possível observar que essa consolidação constitui-se num desafio a ser vencido, considerando o percentual de crianças que não alcançam o "nível adequado em alfabetização" em leitura, escrita e 
Matemática, 22,2\%, 34,4\% e 57,1\% respectivamente. Esse termo "nível adequado em alfabetização" é uma expressão utilizada pelo MEC para definir os níveis de proficiência que as crianças alcançaram ao final do $3^{\circ}$ ano na ANA. Por exemplo, na proficiência em leitura, o MEC estabelece uma escala de leitura distribuída em quatro níveis (1, 2, 3 e 4). Ocorre que o Ministério considera essa proficiência adequada para as crianças que atingiram os níveis 2, 3 e 4. No entanto, ao analisar o conteúdo de cada escala, observa-se que o nível 2 não atende à concepção de alfabetização com letramento aqui apresentada.

Segundo o MEC:

NÍVEL 1 (até 425 pontos). Neste nível, os estudantes provavelmente são capazes de: - Ler palavras com estrutura silábica canônica, não canônica e ainda que alternem sílabas canônicas e não canônicas.

NÍVEL 2 (maior que 425 até 525 pontos) Além das habilidades descritas no nível anterior, os estudantes provavelmente são capazes de: - Localizar informações explícitas em textos curtos como piada, parlenda, poema, quadrinho, fragmentos de narrativas e de curiosidade científica; em textos de maior extensão, quando a informação está localizada na primeira linha do texto. - Reconhecer a finalidade de texto como convite, cartaz, receita, bilhete, anúncio com ou sem apoio de imagem. - Identificar assunto de um cartaz apresentado em sua forma original e ainda em textos cujo assunto pode ser identificado no título ou na primeira linha. • Inferir sentido em piada e em história em quadrinhos que articula linguagem verbal e não verbal. (BRASIL, 2016, p.49).

Ao considerar a descrição do nível 2 como um mínimo suficiente para indicar uma "alfabetização adequada", o MEC equivoca-se, pois não assegura às crianças conhecimentos básicos necessários em leitura para responder às exigências que a própria escola fará na progressão dos seus estudos. Assim, ao realizar uma soma do percentual de crianças que estão incluídas nos níveis 1 e 2, chega-se ao índice de 56,2\%. Ou seja, mais da metade das crianças do $3^{\circ}$ ano do ciclo alfabetizador, em 2014, não atingiram um nível de leitura que condiz com a perspectiva do letramento.

Outra questão a destacar é o fato de que a alfabetização com letramento requer determinadas condições materiais, condições mínimas de infraestrutura que sirvam de apoio pedagógico ao processo de ensino/aprendizagem, tais como bibliotecas, sala de informática, acesso à internet, etc., sobretudo considerando que se vive numa sociedade cada vez mais dominada por novas tecnologias da informação e da comunicação e, para que os sujeitos possam deles se apropriar, precisam ter oportunidades de a eles acessar. 
A escola é um espaço onde essas oportunidades podem ser asseguradas a todos. E para muitas crianças isso ainda não é uma realidade.

De acordo com os dados divulgados pelo Instituto Brasileiro de Geografia e Estatística (IBGE), do Censo Escolar e do SAEB, o Anuário Brasileiro da Educação Básica (TODOS PELA EDUCAÇÃO, 2016a), afirma que em 2014, 43,7\% das escolas públicas brasileiras possuíam biblioteca e/ou sala de leitura, 48,8\% acesso à internet e 49,5\% tinham sala de informática, o que significa que nesses três quesitos relativos à infraestrutura escolar, o Brasil não atingiu 50\% de recursos disponíveis. E quanto à biblioteca, não é suficiente a existência de espaço físico. Ela necessita estar equipada como materiais pedagógicos, com livros, revistas, jornais, pois para grande parte das crianças oriundas das camadas populares o acesso a este material pode ser possível apenas no espaço escolar.

Outro desafio para se efetivar a alfabetização com letramento de qualidade nos três primeiros anos do EF é a materialização do "ciclo" na prática cotidiana das escolas. Sua efetivação exige, dentre outros aspectos, o desenvolvimento de um planejamento articulado, com continuidade na organização dos conteúdos. Entretanto, isso somente será possível se a escola tiver professores trabalhando em determinadas condições de contrato de trabalho, de formação, de apoio didático-pedagógico, etc.

No estado de Santa Catarina, quanto às condições de contrato de trabalho, encontramos a realidade apresentada na Tabela 1.

Tabela 1 - Contratação dos professores do Bloco Alfabetizador de Santa Catarina

\begin{tabular}{|l|c|c|}
\hline Contratação & $\mathbf{N}^{\mathbf{0}}$ de Professores & \% \\
\hline Concursado/efetivo & 8.180 & 48,28 \\
\hline $\begin{array}{l}\text { ACT (Admissão em Caráter } \\
\text { Temporário) }\end{array}$ & 7.899 & 46,62 \\
\hline Terceirizado & 23 & 0,14 \\
\hline $\begin{array}{l}\text { CLT (Consolidação das Leis } \\
\text { do Trabalho) }\end{array}$ & 840 & 4,96 \\
\hline Não informaram & 2 & 0,01 \\
\hline Total & 16.944 & 100 \\
\hline
\end{tabular}

Fonte: Dados do ano de 2013 (SILVEIRA, 2015).

Pode-se observar que, no ano de 2013, quase 50\% dos professores catarinenses das redes estadual e municipal são ACT. Eles atuam numa condição de instabilidade e precariedade funcional, haja vista que a cada ano não possuem garantias de 
permanência no mesmo local de trabalho (escola e turma). Essa vulnerabilidade repercute diretamente na qualidade da educação.

Conforme explicitado, uma educação pautada no ensino em ciclos exige, necessariamente, que o trabalho dos professores aconteça num processo, sem interrupções. Como dar continuidade ao processo de alfabetização, se existe uma rotatividade de professores que ora estão em uma escola, ora estão em outra? E, para as crianças a situação fica ainda mais complicada, porque a troca de professores acaba por interferir no seu processo de aprendizagem, pois a cada novo professor faz-se necessário um novo período de adaptação tanto para ele mesmo como para os alunos.

Ao refletir sobre as condições de trabalho do professor e da relação dessas condições para implantação do ciclo de alfabetização, Arroyo (2001, p.86) afirma que:

Uma hipótese nos persegue: se tivéssemos outros alunos e outros mestres, com outras qualidades, teríamos outras qualidades nos nossos sistemas escolares. Logo, centrar as políticas em conformar outros alunos e outros mestres. Há um dado importante a ponderar: os alunos que chegam às escolas públicas são os mais desiguais entre os desiguais. Por sua vez, os jovens que chegam aos cursos de magistério e de pedagogia têm cada vez mais sua origem social, racial, nos coletivos sociais e raciais tidos como mais desiguais.

Se os professores, atualmente, têm sua origem nas classes mais baixas da sociedade, e considerando que, no sistema capitalista, o acesso aos bens culturais e econômicos é limitado para esses grupos sociais, a educação está ameaçada no que diz respeito à qualidade. Sampaio e Marin (2004), citando estudos realizados pela UNESCO em 2004, revelam que os maiores indicadores nessa área do acesso dos professores brasileiros a bens culturais foram:

[...] $62 \%$ nunca frequentam concerto de música erudita, $14 \%$ não frequentam museus e $17 \%$ não frequentam teatro; $33 \%$ assistem a fitas de vídeo uma vez por semana; $49 \%$ vão ao cinema algumas vezes por ano. [...] apenas 47,9\% lêem revistas especializadas em educação habitualmente ou sempre e 46,5\% lêem às vezes; $\cdot 44,5 \%$ dos professores fotocopiam materiais habitualmente ou sempre e $43,2 \%$ às vezes; $・ 22,9 \%$ compram livros (não didáticos) habitualmente e $58,5 \%$ compram às vezes; $\bullet$ quase $7 \%$ nunca lêem jornais ou revistas; $\bullet 40 \%$ lêem jornal diariamente, $22,6 \%$ lêem de três a quatro vezes por semana e $23,5 \%$ leem uma ou duas vezes por semana (sic). (SAMPAIO; MARIN, 2004, p.1210).

Há outros elementos igualmente importantes - como a valorização social da profissão, os salários, as condições de trabalho, a infraestrutura das escolas, as formas 
de organização do trabalho escolar, a carreira, além da infraestrutura - que devem fazer parte de uma política geral de apoio aos docentes e ao trabalho pedagógico em geral nas instituições escolares.

Estudos de Vaillant (2006, apud GATTI; BARRETO; ANDRÉ, 2011), que discutem a profissão docente no contexto da América Latina, afirmam que nos diferentes países do contexto latino-americano é possível identificar alguns pontos comuns: um entorno profissional que dificulta reter os bons professores na docência; há poucos estímulos para que a profissão seja a primeira opção na carreira; condições de trabalho inadequadas, com problemas sérios na remuneração e na carreira; muitos professores estão muito mal preparados, o que requer esforço massivo de formação em serviço; a gestão institucional e a avaliação dos docentes, em geral, não têm atuado como mecanismo básico de melhoria dos sistemas educativos. Além desses pontos, acrescenta-se o fato de que a grande "maioria do professorado é do sexo feminino", tende a ser mais jovem que nos países desenvolvidos, "provém, em geral, de setores e famílias com menor capital cultural e econômico" em termos relativos e cujo salário contribui com porção significativa da renda familiar, "correspondendo, em alguns países, a $45 \%$ da renda total familiar”. Outro ponto de destaque nesse perfil é que

[...] o preparo e os anos de escolaridade dos docentes latinoamericanos (12 anos) é significativamente menor do que no grupo formado por Estados Unidos, Japão e países da Organização para a Cooperação e Desenvolvimento Económico ou Econômico (OCDE) (16 anos), o que resulta em um comprometimento da educação recebida por crianças e jovens latino-americanos, em especial de contextos socioeconômicos desfavorecidos. (VAILLANT, 2006 apud GATTI; BARRETO; ANDRÉ, 2011, p.18).

Por fim, parece que quando se fala em organizar os três primeiros anos em forma de ciclo, as condições estão dadas, e estão muito próximas dessa ideia de aluno ideal de que fala Arroyo (2001). Ocorre que nem alunos ideais existem como explicou o autor, nem as condições objetivas nas escolas para implantação dos ciclos estão sendo dadas.

\section{Considerações finais}

Os desafios para a concretização de uma alfabetização com letramento numa perspectiva dialética, onde a ampliação da formação escolar seja para atender às 
demandas do desenvolvimento humano e social e não do capital, são diversos e de diferentes naturezas. Neste estudo procurou-se apontar e refletir sobre alguns desafios dentro dos limites que o espaço de um artigo permite.

No Brasil, as reflexões evidenciam que, neste momento, alfabetizar nos anos iniciais do EF, numa perspectiva de alfabetização com letramento já é, por si só, o maior desafio da educação, considerando a realidade na qual se encontram a maioria das escolas públicas, aqui destacadas quanto à universalização do acesso e permanência com qualidade. São significativos os índices de crianças que não aprendem a ler a escrever até o final do terceiro ano do $\mathrm{EF}$, indicando que essas crianças ficarão marginalizadas no processo de escolarização que terão que seguir. Uma educação de qualidade não pode estar definida por uma vinculação imediata e pragmática, nem com o "mercado de trabalho" e nem com o "treinamento" restrito à codificação e decodificação dos sinais gráficos. É fundamental recuperar seu sentido de educação que faculte às crianças e aos jovens as bases dos conhecimentos que lhes permitem analisar, compreender o mundo da natureza, das coisas e o mundo humano/social, político, cultural, estético e artístico.

Propor um EF de nove anos de qualidade, não reduz tão somente a ampliar sua duração. "É preciso qualificar este tempo com concepções pedagógicas e de conhecimento e organização curricular e práticas educativas que garantam aos sujeitos crianças e jovens irem se tornando sujeitos emancipados", o que implica condições dignas de trabalho dos professores e demais profissionais que atuam nas escolas, e materiais pedagógicos adequados. "O que não pode ocorrer é apenas ampliar o tempo, numa escola pública que 'cresce para menos'". (FRIGOTTO, 2015, p.29).

\section{REFERÊNCIAS}

AGUIAR, L. C. Formação docente, política curricular e reedição da Teoria do Capital Humano no Brasil. Cadernos de Pesquisa em Educação, Vitória, v.18, n.36, p.17-38, jul./dez. 2012.

ARROYO, M. G. Ofício de mestre: imagens e autoimagens. 3.ed. Petrópolis: Vozes, 2001.

BRASIL. Instituto Nacional de Estudos e Pesquisas Educacionais Anísio Teixeira. Avaliação Nacional da Alfabetização - ANA. Documento Básico. Brasília: INEP, 2013a. 
BRASIL. Instituto Nacional de Estudos e Pesquisas Educacionais Anísio Teixeira. Indicadores Educacionais. Brasília: INEP, 2014. Disponível em: <http://portal.inep.gov.br/indicadores-educacionais>. Acesso em: 6 nov. 2015.

BRASIL. Instituto Nacional de Estudos e Pesquisas Educacionais Anísio Teixeira. Microdados do Censo da Educação Superior 2013 e 2014. Brasília: INEP, 2013b. Disponível em: <http://portal.inep.gov.br/basica-levantamentos-acessar>. Acesso em: 2 jun. 2015.

BRASIL. Ministério da Educação. Lei n ${ }^{\circ} 11.274$, de 6 de fevereiro de 2006. Altera a redação dos artigos. 29, 30, 32 e 87 da Lei ${ }^{\circ}$ 9.394, de 20 de dezembro de 1996, que estabelece as Diretrizes e Bases para a Educação Nacional, dispondo sobre a duração de 9 (nove) anos para o Ensino Fundamental, com matrícula obrigatória a partir dos 6 (seis) anos de idade. Diário Oficial da União, Brasília, 7 fev. 2006. Disponível em: <http://www.planalto.gov.br/ccivil_03/_ato2004-2006/2006/lei/111274.htm>. Acesso em: 17 abr. 2014.

BRASIL. Ministério da Educação. Parecer CNE/CEB n 4/2008, de 20 de fevereiro de 2008. Orientação sobre os três anos iniciais do Ensino Fundamental de nove anos. Diário Oficial da União, Brasília, 10 jun. 2008. Disponível em: <http://portal.mec.gov.br/cne/arquivos/pdf/2008/pceb004_08.pdf>. Acesso em: 2 jun. 2015.

BRASIL. Ministério da Educação. Resolução CNE/CEB nº 7/2010, de 14 de dezembro de 2010. Fixa Diretrizes Curriculares Nacionais para o Ensino Fundamental de 9 (nove) anos. Diário Oficial da União, Brasília, $15 \mathrm{dez}$. 2010. Disponível em: <http://portal.mec.gov.br/dmdocuments/rceb007_10.pdf〉. Acesso em: 2 jun. 2015.

BRASIL. Ministério da Educação. Decreto $n^{\circ}$ 6.094, de 24 de abril de 2007. Dispõe sobre a implementação do Plano de Metas Compromisso Todos pela Educação, pela União Federal, em regime de colaboração com Municípios, Distrito Federal e Estados, e a participação das famílias e da comunidade, mediante programas e ações de assistência técnica e financeira, visando a mobilização social pela melhoria da qualidade da educação básica. Diário oficial [da] República Federativa do Brasil, Brasília, 25 abr. 2007.

BRASIL. Ministério da Educação. Ensino Fundamental de nove anos: passo a passo do processo de implementação. Brasília: Secretaria de Educação Básica, 2009.

BRASIL. Ministério da Educação. Lei no 9.424 de 24 de dezembro de 1996. Dispõe sobre o Fundo de Manutenção e Desenvolvimento do Ensino Fundamental e de Valorização do Magistério. Brasília: Ministério da Educação, 2001a.

BRASIL. Ministério da Educação. Lei $n^{\circ} 10.172$, de 09 de janeiro de 2001. Aprova o Plano Nacional de Educação (PNE). Diário Oficial da União [da] República Federativa do Brasil, Brasília, DF, 10 jan. 2001 b.

BRASIL. Ministério da Educação. Lei $\mathrm{n}^{\circ} 11.114$, de 16 de maio de 2005. Altera os artigos. $6^{\circ}, 30,32$, e 87 da Lei $n^{\circ} 9.394$ de 20 de dezembro de 2006, com o objetivo de 
tornar obrigatório o início do ensino fundamental de seis anos de idade. Diário Oficial da União, Brasília, 16 mai. 2005.

BRASIL. Ministério da Educação. Parecer CNE/CEB no 4/2008, de 20 de fevereiro de 2008. Reafirma a importância da criação de um novo ensino fundamental, com matrícula obrigatória para as crianças a partir dos seis anos completos ou a completar até o início do ano letivo. Brasília: Ministério da Educação, 2008.

BRASIL. Ministério da Educação. Relatório de Gestão 2004. Brasília: Conselho Nacional de Educação, 2004. Disponível em: <http://portal.mec.gov.br/cne/arquivos/pdf/relgestao_04.pdf〉. Acesso em: 17 abr. 2014.

CALLEGARI, C. Radicalizar o pacto pelas crianças do Brasil. São Paulo: IBSA Instituto Brasileiro de Sociologia Aplicada, 2015. Disponível em: <http://www.ibsa.org.br/radicalizacao.php>. Acesso em: 13 ago. 2016.

FINKEL, S. M. Crise de acumulação e resposta educacional da nova direita. Teoria \& Educação, Porto Alegre, n.2, p.3-18, 1990.

FRIGOTTO, G. Os sujeitos da escola pública e o ensino fundamental de nove anos: dimensões ético-políticas e pedagógicas. Belém: Secretaria de Educação, 2015. Disponível em: <www.seduc.pa.gov.br>. Acesso em: 13 ago. 2016.

GATti, B. A.; BARRetTo, E. S. S.; ANDRÉ, M. E. D. A. Políticas docentes no Brasil: um estado da arte. Brasília: UNESCO, 2011.

GENTILI, P.; SILVA, T. T. (Org.). Neoliberalismo, qualidade total e educação: visões críticas. Petrópolis: Vozes, 2007.

OLIVEIRA, D. Educação básica: gestão do trabalho e da pobreza. Petrópolis: Vozes, 2000.

PERONI, V. M. V. Dilemas da educação brasileira em tempos de globalização neoliberal: entre o público e o privado. Porto Alegre: Ed. da UFRGS, 2006.

SAMPAIO, M. M. F.; MARIN, A. J. Precarização do trabalho docente e seus efeitos sobre as práticas curriculares. Educação \& Sociedade, Campinas, v.25, n.89, p.12031225, set./dez. 2004.

SHIROMA, E. O.; MORAES, M. C. M.; EVANGELISTA, O. Política educacional. Rio de Janeiro: DP\&A, 2002.

SILVEIRA, C. M. O perfil dos professores alfabetizadores das escolas públicas de Santa Catarina. 2015. 112 f. Dissertação (Mestrado em Educação) - Universidade do Sul de Santa Catarina, Tubarão, 2015.

SOARES, M. Alfabetização e letramento. São Paulo: Contexto, 2003.

SOARES, M. Letramento: um tema em três gêneros. 2.ed. Belo Horizonte: Autêntica, 2004. 
TODOS PELA EDUCAÇÃO (Org.). Anuário Brasileiro da Educação Básica 2016. São Paulo: Moderna, 2016.

TODOS PELA EDUCAÇÃO (Org.). Microdados - SAEB/INEP: análises. [S.1.]: Todos Pela Educação, 2016. Disponível em: <http://www.todospelaeducacao.org.br/ $\geq$. Acesso em: 13 ago. 2016.

TFOUNI, L.V. Letramento e alfabetização. 8.ed. São Paulo: Cortez, 2006.

UNESCO. Declaração Mundial sobre Educação para todos: plano de ação para satisfazer as necessidades básicas da aprendizagem. Jomtien/Tailândia: UNESCO, 1990. Disponível em: 〈https://www.unicef.org/brazil/pt/resources_10230.htm〉. Acesso em: 14 dez. 2016.

\section{Como referenciar este artigo}

SCHMIDT, Leonete Luzia; AGUIAR, Letícia Carneiro. A alfabetização no ensino fundamental de nove anos no contexto das políticas educacionais: alguns desafios para reflexão. Revista Ibero-Americana de Estudos em Educação, Araraquara, v.11, n. esp. $\quad 4, \quad$ p. 2395-2413, 2016. Disponível em: <http://dx.doi.org/10.21723/riaee.v11.n.esp4.9200>. E-ISSN: 1982-5587.

Submetido em: agosto/2016

Aprovado em: novembro/2016 